\title{
As estratégias de diversificação dos meios de vida e a formação da renda: uma análise empírica sobre os estabelecimentos agrícolas familiares cooperados da Cresol Prudentópolis ${ }^{1}$
}

\author{
Simão Ternoski* \\ Miguel Ângelo Perondi**
}

\begin{abstract}
Resumo
As estratégias de renda pautadas na diversificação dos meios de vida estão associadas à formação da renda dos estabelecimentos. Assim, a teoria que norteia este estudo aborda as diferentes estratégias da vida no meio rural, principalmente em relação ao tema da pluriatividade. Como hipótese admite-se que o agricultor com fonte de renda mais diversificada apresenta uma menor vulnerabilidade e uma maior renda total e agrícola. A metodologia consiste na pesquisa explicativa, de caráter quantitativo, a partir do emprego de técnicas de amostragem e de métodos estatísticos (teste $t$ e regressão). Como resultado, identificouse que: (1) a diversificação dos meios de vida, expressa na pluriatividade, permite aos estabelecimentos, de acordo com o teste $t$, níveis de renda mais elevados; (2) a variável binária, preditora, por meio do modelo de regressão simples, apresentou explicação da variável dependente renda agrícola, mas não explica a variável dependente renda total. Concluise que a pluriatividade está ligada a níveis mais elevados de renda, mas sem explicar a formação da renda total.
\end{abstract}

Palavras-chave: Pluriativos. Agricultura familiar. Tipificação. Diversificação da renda. Monoativos.

Mestre em Desenvolvimento Regional pela Universidade Tecnológica Federal do Paraná (UTFPR). Professor do Departamento de Ciências Econômicas da Universidade Estadual do Centro-Oeste (Unicentro). E-mail: simaoternoski@yahoo.com.br

* Professor da Universidade Tecnológica Federal do Paraná. Engenheiro Agrônomo, Mestre em Administração e Doutor em Desenvolvimento Rural. 


\section{Introdução}

A formação e a composição da renda rural nos pequenos estabelecimentos agrícolas estão relacionadas, segundo Schneider (2010), Perondi e Schneider (2012) e Fuller (1990), dentre outros autores detalhados neste estudo, com as estratégias de diversificação dos meios de vida, o que requer esforços no sentido de ampliar as capacitações em busca de uma maior potencialidade do viver. Discutir a formação da renda é avançar na compreensão das estratégias que as famílias rurais adotam para atingir um maior nível dessa renda. As estratégias estão relacionadas desde às atividades agrícolas desenvolvidas, até os trabalhos para fora do estabelecimento, tanto agrícolas como não agrícolas.

No meio rural existe uma tendência das famílias a assumirem inúmeras ocupações, tanto dentro do próprio estabelecimento, bem como em estabelecimentos vizinhos ou então no centro urbano. Obter rendas de fora do estabelecimento, de fontes agrícolas ou não agrícolas, é avançar na pluriatividade, que se torna tanto uma opção de sobrevivência para muitas famílias, como também uma estratégia de acumulação de capital para outras. Assim, pergunta-se: as estratégias de diversificação dos meios de vida adotadas pelas famílias rurais conseguem elevar a renda e reduzir as vulnerabilidades?

As análises teóricas e empíricas terão por pressuposto verificar a seguinte hipótese: (1) agricultor com fonte de renda mais diversificada apresenta uma menor vulnerabilidade e uma maior renda total e agrícola. Para tanto, é objeto desta investigação, analisar as estratégias de meios de vida e a sua relação na formação da renda no meio rural entre os cooperados da Cooperativa de Crédito Rural com Interação Solidária (Cresol) Prudentópolis-PR. Especificamente: (1) mensurar a composição da renda total dos estabelecimentos amostrados; (2) classificar os estabelecimentos de acordo com a sua tipificação, em monoativos e pluriativos; (3) relacionar à tipologia dos estabelecimentos à renda total e à renda agrícola; (4) comparar, a partir dos testes estatísticos, a média de renda para cada um dos grupos; (5) determinar a explicação da renda (variável dependente), por meio de um modelo de regressão simples, em relação à característica pluriativa e monoativa (variável preditora).

Assim, a importância deste estudo se dá em decorrência ao contexto de análise, estando inserido no território Centro-Sul, que figura em destaque que todos os municípios apresentam Índice de Desenvolvimento Humano (IDH) abaixo da média brasileira. Os municípios estudados apresentam concentração populacional em áreas rurais com produção de commodities agrícolas alimentares e não alimentares 
vendidas in natura. Uma agricultura nesses moldes, baseada em atividades de baixa remuneração do trabalho, resulta em uma sociedade de baixo nível de consumo e corresponde ao que Ellis (2000) denomina de "pessoal com pobreza de consumo".

Cabe ao estado, segundo Ellis (2000) coordenar políticas de diversificação e agregação de valor, como, por exemplo, incentivar grupos a produzir localmente e vender, como melhorar as estratégias de meios de vida das famílias e consequentemente contribuir na melhoria da renda no meio rural. Nesse aspecto, essa proposta ao identificar as estratégias de meios de vida a partir da tipificação dos estabelecimentos, pode contribuir na formação de políticas públicas voltadas principalmente às regiões agrícolas, no sentido de melhorar a formação da renda nesse meio .

Além desta introdução, o artigo apresenta na seção 2 uma fundamentação teórica a respeito das estratégias de meios de vida e da pluriatividade, na seção 3 estão apresentados os procedimentos metodológicos seguidos da seção item $4 \mathrm{em}$ que são apresentados os resultados e as discussões. Na seção 5, o artigo apresenta as conclusões.

\section{Fundamentação teórica}

A abordagem teórica deste estudo que fundamenta e justifica o problema da pesquisa, está relacionada com as teorias sobre as estratégias dos meios de vida no meio rural, abordando principalmente o tema da pluriatividade e dos mercados.

\subsection{Os mercados e a commoditização dos estabelecimentos rurais}

O surgimento das economias de mercado, na passagem do sistema feudal para o capitalismo (Século XI ao XV) transferiu o centro da vida econômica, social e política dos feudos para as cidades e, ao mesmo tempo, promoveu a integração da produção a um mercado global, elevando os riscos a que os agentes produtivos estão expostos. As economias de mercado, fruto do capitalismo, para Marx (1996), transformam as relações sociais e os fatores de produção em mercadoria, inclusive o que antes não era considerado mercadoria.

Para Polanyi (1977), o sentido da mercadoria foi alterado com o capitalismo, as quais eram o que o termo em seu sentido genuíno quer expressar, ou seja, eram mercadorias apenas, mas que a partir das economias de mercado tudo passa a ser uma mercadoria, inclusive as relações sociais. 
A criação dos mercados fez com que os homens direcionassem suas ações em torno de um sentido econômico, em busca da satisfação de suas necessidades e visando sempre a atingir o lucro. Essa junção gera um sistema de produção, "enquanto um indivíduo está 'obtendo rendimento', ele está automaticamente contribuindo para a produção", o sistema somente funciona se os indivíduos tiverem razões para isso (POLANYI, 1977, p. 6).

As economias de mercado impactaram em todos os setores produtivos, e na agricultura não foi diferente. Em sua teoria da commoditização, Long (1986) avalia os impactos da comercialização e da integração das famílias na economia capitalista. Em Marx (1996) já havia a discussão de commodities, consideradas como todos os produtos com utilidade e com algum valor de troca, expressa no momento da comercialização.

Os impactos das commodities, na vida social, são analisados por Marx de forma ampla, com a análise de que tudo torna-se mercadoria, inclusive o trabalho humano que passa a ser direcionado para a produção de commodities. A justificativa da commoditização no capitalismo seria uma maneira de mascarar a exploração do trabalhador (LONG, 1986).

As famílias estão cada vez mais ligadas ao mercado e, de acordo com Long (1986), é crescente o número de famílias que, para satisfazer suas necessidades de consumo, comercializam commodities, ou vendem sua força de trabalho para fora do estabelecimento. Dentro desse modelo de produção agrícola, surge uma "fome por dinheiro", sendo possível verificar até mesmo o nível de mercantilização a partir de uma base na subsistência e na estratégia de commodities simples.

A teoria da commoditização em Long (1986) e a integração aos mercados em Friedmann (1978) indicam as vulnerabilidades enfrentadas pela agricultura familiar frente às oscilações dos preços dos mercados. Estabelecimentos agrícolas que adotam estratégias voltadas à produção de uma commoditie ou que concentram seu portfólio na produção de um ou dois produtos estão mais vulneráveis tanto aos riscos climáticos quanto às oscilações mercadológicas. Estabelecimentos com essas características são comumente denominados de monoativos.

Já a pluriatividade está na característica inversa da monoatividade, refere-se a estabelecimentos que buscam diversificar as estratégias, obter também rendas não agrícolas. A pluriatividade, no contexto da agricultura familiar, torna-se positiva ao reduzir os riscos e as vulnerabilidades enfrentadas pelas famílias.

As estratégias de renda das famílias rurais pautadas na produção de commodities elevariam as vulnerabilidades dos estabelecimentos rurais, mas as estratégias de diversificação dos meios de vida, segundo Schneider (2010) ampliam 
as opções que se apresentam as famílias. Um exemplo são as regiões agrícolas produtoras de commodities, que além dos riscos climáticos, podem sofrer com as situações adversas do mercado, ou com as oscilações dos preços que impactam diretamente sobre os lucros.

\subsection{Estratégias dos meios de vida no rural}

Ampliar as alternativas de renda ou as opções das fontes de renda é incorrer na diversificação das estratégias, reduzindo, assim, a produção de commodities. Ellis (2000), Schneider (2010) e Perondi e Schneider (2012), além de outras vertentes teóricas apontam a importância da diversificação dos meios de vida no processo de combate a pobreza ao elevar a renda e reduzir as vulnerabilidades enfrentadas por essas famílias. Expandir as opções de renda de um estabelecimento é proporcionar alternativas de escolhas frente aos riscos.

A importância da diversificação dos meios de vida frente à redução da miséria está retratada em Ellis (2000), no seu argumento de que as políticas de diversificação são na verdade políticas de combate a pobreza, mas essa não em um sentido de dinheiro, mas de capacidades ou de restrições de acesso aos recursos.

As capacidades de acesso são fundamentais para fortalecer os meios de vida, Schneider (2010) as considera como mecanismos que diversificam as estratégias e condicionam o trabalho e a renda, reduzindo o risco e a vulnerabilidade do ambiente hostil que os agricultores estão inseridos. Estabelecimentos com fontes de renda mais diversificada são capacitados de maiores oportunidades de escolhas que fazem frente aos riscos do ambiente.

As vulnerabilidades e a pobreza podem ser combatidas por meio do processo de diversificação dos meios de vida, o que se configura como uma estratégia para fazer frente às situações de precariedade e de crise. Novas alternativas ou mesmo a ampliação das opções seriam estratégias de adaptação e de escolha a que populações pobres recorreriam para fazer frente aos problemas de miséria (PERONDI; SCHNEIDER, 2012).

Entender a estratégia de formação da renda rural é um primeiro passo para reduzir a pobreza. Para Ellis (2000), as rendas vêm de estratégias que, muitas vezes, não envolvem o estabelecimento agrícola, pois, pode haver trabalhos agrícolas para fora da propriedade, ou mesmo, de rendas não agrícolas.

Rendas provenientes de atividades não agrícolas ou resultantes de trabalhos agrícolas para fora da unidade de produção caracterizam os estabelecimentos rurais como pluriativos. Um questionamento levantado em Silva e Kodithuakku 
(2010) está em entender até que ponto as práticas pluriativas, observadas nos estabelecimentos agrícolas, leva as famílias rurais a serem social e economicamente melhores. O que pode ser observado, em muitos casos, é uma prática de trabalhos para fora da unidade de produção como uma estratégia de sobrevivência e não propriamente uma estratégia de acumulação de capital.

Em revisão em Silva e Kodithuwakku (2010), Sofer (2001), Loughrey et al. (2013), Jervell (1999) e Blad (2010) é possível verificar certo consenso de que as práticas pluriativas podem ser tanto adotadas no sentido da sobrevivência, como também em uma prática de acumulação de capital, uma estratégia da família. Bowler et al. (1996) identifica a pluriatividade como estratégia de sobrevivência, já Mcnally (2001) como estratégia de acumulação de capital.

Para tanto, Silva e Kodithuwakku (2010) consideram a pluriatividade como o resultado do ambiente hostil, o qual força os agricultores a buscar novas fontes de renda para sobreviver e reduzir os riscos e as flutuações da renda resultantes da especialização. Mas existem outros fatores como a falta de ocupação em tempo integral ou as pressões populacionais nas áreas agrícolas que contribuiriam para as práticas pluriativas, fatores esses apontados por Gilad e Levine (1986) como empurradores, ou seja, relacionados à sobrevivência.

Do lado da acumulação de capital os lucros seriam reinvestidos, gerando, então, os benefícios econômicos e sociais tanto para o indivíduo como para a comunidade, tais forças Gilad e Levine (1986) denominam como uma força que puxa. Silva e Kodithuwakku (2010) avançam nesse ponto, demonstrando que os agricultores pluriativos levados pelas forcas de puxar são mais bem-sucedidos do que aqueles que são levados pelas forcas de empurrar, uma vez que os últimos buscam apenas a sobrevivência.

Fuller (1990) considera a pluriatividade como o resultado do envolvimento do agricultor nas mais variadas atividades de geração de renda. Neste ponto, é importante colocar alguns conceitos-chave que ajudam a entender a pluriatividade e a diversificação. Em Loughrey et al. (2013) existe uma revisão na ampla literatura sobre o assunto que consideram duas formas de pluriatividade; uma relacionada à diversificação de dentro das porteiras da propriedade, ou seja, as múltiplas ocupações de pecuária, agrícola e florestais referindo-se a diversificação agrícola, muitos autores consideram como práticas monoativas; e, outra forma como a diversificação relacionada às atividades de dentro das porteiras da propriedade, mas que não são agrícolas ou não se relacionam diretamente à terra, como exemplo do turismo rural ou processamento de alimentos; por fim, existe ainda os trabalhos para fora do estabelecimento, trabalhos não agrícolas remunerados ou então relacionados ao autoemprego. 
As práticas agrícolas são descritas em Knickel et al. (2003) e Durand e Van Huylenbroeck (2003) como pluriativas e diversificadas. Pluriatividade no sentido de rendas inclusive não agrícolas, e diversificadas relacionadas ao local de trabalho ou às técnicas produtivas, podendo avançar sobre atividades não agrícolas, combinando diversificação com pluriatividade. Blad (2010) considera que existe certo consenso de pesquisadores, os quais apontam a diversificação como relacionada exclusivamente a atividades realizadas no contexto do estabelecimento familiar ou ao uso da terra e do capital do estabelecimento agrícola.

A diversificação seria, então, um subgrupo da pluriatividade, que em Blad (2010) abrangeria todas as formas de geração de renda não agrícola, podendo ser na própria exploração ou fora da exploração das atividades agrícolas. A autora aponta a pluriatividade em três casos, nas quais o agricultor: (1) é empregado em uma empresa não agrícola; (2) é empregado em outra exploração agrícola; (3) ou, então, criou atividades diversificadas que não incluem trabalho agrícola, como o turismo ou o artesanato, em seu estabelecimento.

Para a Comissão Europeia (CE) (2008), a pluriatividade é tratada como casos onde o agricultor exerce trabalhos não agrícolas remunerados tanto no próprio estabelecimento, em outros estabelecimentos vizinhos ou, então, como empregado em empresas não agrícolas. A diversificação dos meios de vida, neste sentido, contribuiria para diferenciar o modo de vida de um estabelecimento rural entre pobre e miserável, quanto mais diversificada, ou quanto mais o estabelecimento avançar na pluriatividade menores as incertezas e as vulnerabilidades ao ambiente externo.

O sentido da pluriatividade, para Blad (2010), vem se alterando ao longo do tempo, e as práticas pluriativas viriam desde a época em que as famílias levavam em seu nome suas habilidades. Muitas dessas práticas ou pequenas oficinas foram extintas com o início da industrialização, mas que não conseguiu extinguir as práticas pluriativas, as quais receberam uma nova roupagem, na qual os agricultores passaram a inserir-se nas atividades industriais.

Barlett (1998) aponta três caminhos principais para a pluriatividade: (1) como uma forma intermediária entre a expansão ou o abandono da agricultura; (2) como entusiastas do estilo de vida rural, com benefícios da vida no campo e benefícios econômicos de rendas não agrícolas, mantendo o estabelecimento como passatempo e não como comercial; (3) como elemento relativamente estável de uma estratégia do agricultor familiar, buscando elevar a renda da família.

Mas para Blad (2010, p. 164, tradução própria) "a pluriatividade não é uma forma intermediária entre a expansão da propriedade ou o abandono. É uma forma de manter as duas formas de atividade, ao mesmo tempo - tanto dentro ou fora 
do estabelecimento. [...] a pluriatividade é uma estratégia de sobrevivência e de elevação de renda".

Os estudos de Sofer (2001) no Moshav, ${ }^{2}$ na região de Sharon em Israel, demonstram que a adoção da pluriatividade se dá primeiramente devido à redução da renda agrícola, seguida pela vocação de explorar uma atividade não agrícola e, em terceiro grau, decorrente das instalações e terrenos não utilizados.

Os motivos para que as famílias tornem-se pluriativas vão desde o aumento da eficiência e tecnificação da agricultura e aumento da oferta de alimentos, o que reduz a demanda de trabalho e os incentivos, forçando os pequenos agricultores a buscar outras ocupações; elevação de custos e queda relativa de preços, reduzindo lucros; capacitação dos agricultores, elevando as possibilidades de ocupar atividades; melhoria da infraestrutura, que possibilita o fluxo de pessoas das áreas rurais para o urbano e o acesso a atividades não agrícolas (SOFER, 2001).

Corroborando com a discussão, no Brasil os estudos de Schneider (2003) apontam que a pluriatividade poderia elevar os rendimentos e reduzir os índices de pobreza, o espaço rural deixaria de ser sinônimo de atraso e se desconectaria da agricultura, que passaria a ser apenas uma de suas atividades.

Espaços ineficientes ou práticas agrícolas com o uso inadequado dos fatores de produção geram rendimentos baixos e inviabilizam as práticas agrícolas. Para Jervell (1999) esses motivos podem levar às práticas pluriativas, mas a proporção da pluriatividade varia também em relação ao local e a oferta de trabalho. Em Schneider (2010) é possível verificar um diagrama que pode ser visualizado na Figura 1 e que auxilia no entendimento das práticas comuns nos estabelecimentos agrícolas. 
Figura 1 - Organograma de tipificação das rendas

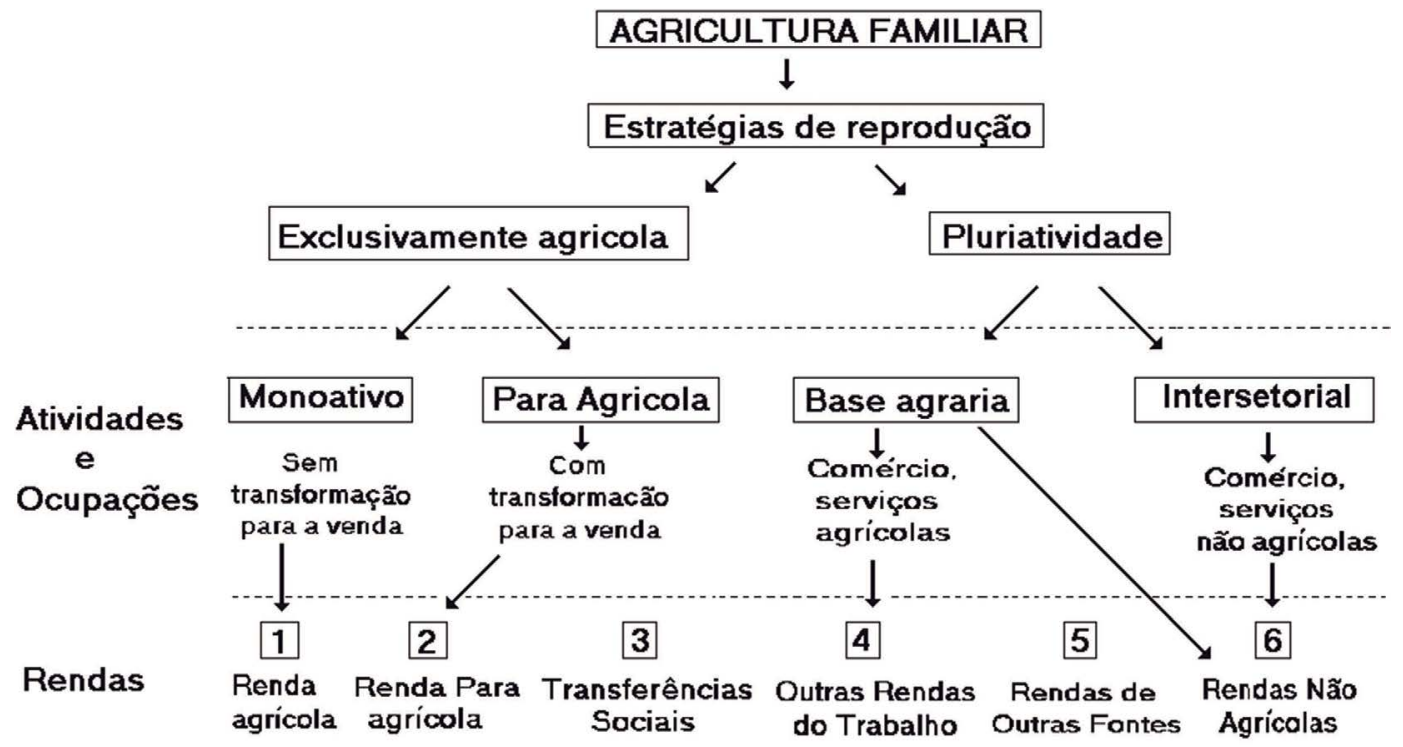

Fonte: Schneider (2010, p. 97).

A formação das rendas não decorre somente das atividades agrícolas, conforme Figura 1, mas também de rendas não agrícolas e para-agrícolas. O processo de diversificação, de acordo com Perondi e Schneider (2012, p. 20), pode "representar uma alternativa viável para saída da pobreza ou vulnerabilidade em que se encontram as populações".

A diversificação está relacionada às estratégias pluriativas adotadas nos estabelecimentos. Schneider (2010) considera que os métodos exclusivamente agrícolas podem ser tanto monoativos, sem que ocorra a transformação para a venda e a geração de rendas, como também para- agrícolas, ocorrendo a transformação para a venda e a geração de renda, ambos os casos, o estabelecimento trabalha exclusivamente em atividades agrícolas.

A pluriatividade faz com que os indivíduos de um estabelecimento rural passem a dedicar-se a outras atividades que não são cotidianas fora do seu estabelecimento. Conforme Baumel e Basso (2004, p. 144), a pluriatividade deve ser encarada como a "emergência de situações sociais em que os indivíduos que compõem uma família com domicilio rural passam a dedicar-se ao exercício de um conjunto variado de atividades econômicas e produtivas”. 
Na pluriatividade, além das estratégias já mencionadas, a família conta com rendas de base agrária, formada pelo comércio de serviços agrícolas e venda do trabalho, como também do trabalho intersetorial, com o comércio de trabalho não agrícola, isto é, quando membros do estabelecimento trabalham em atividades não agrícolas ou nos centros urbanos, mas residem no estabelecimento rural (SCHNEIDER, 2010).

A renda total é formada ainda por aposentadorias, transferências, juros e outros benefícios sociais ou de qualquer outra fonte. Para Kageyama (2001), o peso das rendas não agrícolas para com a renda total não apresenta um padrão estável e pode variar em muito de acordo com as regiões, além disso a relevância cai à medida do crescimento da renda total.

Dentro do contexto rural, segundo Estada (2003, p. 199) existe uma semelhança de termos entre a agricultura em tempo parcial e a pluriatividade, ambas com significados próximos. A agricultura de tempo parcial é tratada como uma categoria social de agricultores que "em geral o titular de uma pequena exploração, divide sua atividade produtiva entre o trabalho agrícola dentro de seu estabelecimento e o trabalho não agrícola em setores diversos da economia".

Embora exista certa semelhança no conceito, ambos seguiram dentro das agendas políticas e sindicais rumos bastante distintos. Enquanto a agricultura em tempo parcial foi percebida como aspecto negativo nos anos de 1960 e 1970 para a modernização produtiva, a pluriatividade atualmente é valorada positivamente para a sustentabilidade dos espaços rurais (ESTADA, 2003).

A tendência das famílias rurais é estarem inseridas em múltiplas ocupações, mas muitas famílias rurais pobres por si só são incapazes de prover sua própria subsistência. Os fatores que levam as famílias a adotar carteiras diversificadas são inúmeros, como falhas dos mercados de crédito, choques externos e suavização do consumo, entre outros, que contribuem ao longo do tempo para a diversificação dos meios de vida rural. Essas implicações políticas, muitas vezes, em ambiente macro não são compreendidas, ao passo que em longo prazo gera efeitos diversos nas práticas dessa família (ELLIS, 2000).

Algumas correntes apontam e até mesmo questionam a excessiva parcela de mão de obra liberada da agricultura, como no modelo de Lewis, em que segundo Souza (2012), os governos deveriam incentivar a fixação do homem no campo, e também trazer esse de volta, por meio de financiamentos para irrigação, estradas, escolas, etc. Os investimentos deveriam, acima de tudo, incentivar a formação dos vários capitais, que seriam tão produtivos quanto os investimentos em capital físico.

A quantidade de oferta de mão de obra agrícola destinada ao setor industrial depende do valor dos salários fixados no meio urbano. $\mathrm{O}$ fator de transferência 
de mão de obra decorre da tendência a zero da produtividade marginal $(P m g)$ do trabalho agrícola. Esse fator faz com que mesmo com o emprego de um integrante da unidade familiar no meio urbano, as atividades de cultivo continuam sendo desempenhadas na mesma proporção e sem grandes esforços. A busca por trabalhos em atividades para fora da unidade de produção ocorre devido aos salários urbanos serem fixados acima do nível de subsistência agrícola ${ }^{3}$ (SOUZA, 2012).

A atratividade dos trabalhos para fora do estabelecimento agrícola atrai os interesses das populações rurais, e vem se tornando um fator positivo, permitindo ao estabelecimento rural avançar na pluriatividade. No entanto, existem diferenças entre a diversificação em nível doméstico e em nível individual. Para Ellis (2000), do ponto de vista individual, a pessoa pode ter ocupações diversas e em tempo parcial, e, muitas vezes, são mal pagas, trazendo insegurança, e a diversificação individual está associada à pobreza.

$\mathrm{Na}$ diversificação do estabelecimento produtivo, as famílias diversificam a carteira de atividades e os indivíduos especializam-se e trazem uma maior segurança para o conjunto familiar. No primeiro, o indivíduo busca a diversificação como uma forma de subsistência, geralmente, relacionada a um trabalho desfavorável. $\mathrm{Na}$ família, relaciona-se à especialização de cada indivíduo daquela unidade que trará renda maior ao conjunto familiar diversificado.

A diversificação dos meios de vida é apresentada por Ellis (2000) em alguns pontos. O primeiro está relacionado à extensão da diversificação, as porcentagens de rendas não agrícolas variam entre as famílias de acordo com a quantidade de capitais, e o aumento da renda diminui a dependência da agricultura, quanto mais diversificada melhor é o nível de renda e a situação da família. O segundo ponto diz respeito à pobreza e a distribuição de renda, logo a diversificação é benéfica às famílias de baixa renda, e o simples fato de se ter alternativas para diversificar pode fazer diferença entre um meio de vida minimamente viável e a miséria.

Mas, a diversificação não significa uma distribuição de renda equitativa, muito pelo contrário, a tendência das famílias mais ricas se sobressaírem sobre as mais pobres é grande, uma vez que o acesso aos capitais poder se maior. Os reflexos da diversificação, segundo Ellis (2000), variam de região para região, em relação à agricultura e ao meio ambiente e podem gerar ou não maior percentual de rendas não agrícolas, bem como, reduzir ou elevar a exploração dos recursos naturais.

No contexto das capacidades das famílias apresentado em Ellis (2000) como capitais, Silva e Kodithuwakku (2010) levantam novamente a questão de que nem todas as famílias pluriativas acumulam riquezas. Em seus estudos, foi verificado que fatores climáticos conduzem as famílias para a pluriatividade, tanto as mais ricas como as mais pobres. Os autores chegam à conclusão de que no primeiro 
momento tornar-se pluriativo foi uma estratégia de sobrevivência para ambos, mas que com o passar do tempo os motivos tornaram-se diferentes.

A conclusão que Silva e Kodithuwakku (2010) chegaram é que para as famílias em pior situação a pluriatividade foi usada para a sobrevivência, as quais voltaram aos cultivos normais no tempo de clima favorável. Já as famílias de melhor situação entenderam as possibilidades de ganhos e adotaram as práticas pluriativas como uma estratégia de acumulação.

A diferença apontada por esses autores está na qualidade da diversificação, ambas eram pluriativas, mas apenas uma parte reinveste os lucros e adia o consumo, obtendo maiores retornos no longo prazo. Essa tendência leva Silva e Kodithuwakku (2010) a perceber uma alteração, no longo prazo, dos motivos que levam a pluriatividade, iniciando com a sobrevivência, que pode tranformar-se em uma atração para algumas famílias, mas que para outras pode continuar inalterada.

Os modos de vida mais diversificados contribuem para o aumento da segurança, principalmente em longo prazo por permitir facilmente adaptações e substituições de sistemas decadentes. Ellis (2000) aponta a diversificação como benéfica na redução dos efeitos das sazonalidades, uma vez que as atividades agrícolas geram picos de utilização de trabalho, concentrando a renda agrícola em determinados períodos, a diversificação reduziria tais efeitos, possibilitando rendas alternativas fora dos períodos de pico dos ciclos agrícolas.

Em um sentido amplo, a diversificação também reduz os riscos sobre todas as atividades, o fator de risco varia de uma atividade para outra. Com a diversificação dos meios de vida os níveis de renda são mais elevados, estão acima dos níveis de renda encontrados nas estratégias exclusivamente agrícola, além de aperfeiçoar os recursos e a força de trabalho expressas na sazonalidade (ELLIS, 2000).

\section{Procedimentos metodológicos}

A pesquisa busca a partir do emprego de alguns métodos validar as observações dos dados com referência às teorias já existentes. Faz uso de alguns procedimentos apresentados em Beuren (2004), Merrian (1998), Richardson (2008) e Matos (1997). Emprega o uso da pesquisa documental e o exame de um grupo social específico, representado pelos cooperados da Cresol Prudentópolis a partir do banco de dados de Ternoski (2013).

O tratamento dos dados segue de acordo com Beuren (2004), Merrian (1998) e Richardson (2008) o método quantitativo por meio de técnicas estatísticas para a análise dos dados, onde foi empregado por Ternoski (2013) técnicas de amostragem 
e procedimentos de seleção dos casos. Este estudo utiliza-se destes dados para realizar inferências, buscando atender aos objetivos propostos, portanto, a pesquisa, segundo a literatura caracteriza-se como explicativa ao realizar inferências no sentido de explicar a determinação da renda.

O contexto estudado refere-se aos municípios de Prudentópolis e Guamiranga inseridos no território Centro-Sul do estado do Paraná. A concentração populacional nas áreas rurais do território é um dos fatores que contribui para a pobreza, com exceção de Imbituva e Irati com população urbana maior que a rural, em todos os demais municípios as taxas de pobreza rural são mais elevadas que as taxas urbanas, ou seja, 36,7\% das famílias são consideradas pobres, índice superior à média paranaense de 20,9\%. A taxa de pobreza é maior quanto menos urbanizada é a cidade (IPARDES, 2007; IBGE, 2012).

A produção em ambos os municípios, Prudentópolis e Guamiranga, foco do estudo, se dá principalmente em torno de produtos in natura, dentre esses as commodities alimentares como o milho, a soja e o feijão. É destaque a produção de commodities não alimentares, neste caso o tabaco em folha, que corresponde a $57 \%$ do percentual em unidades monetárias da produção de Guamiranga e a 35\% do percentual de Prudentópolis. Tanto as commodities alimentares como não alimentares são vendidas in natura e apresentam baixo valor agregado (IPARDES, 2012a; IPARDES, 2012b).

Os estabelecimentos agrícolas investigados se resumem a uma amostra de 114 casos dos 1.429 estabelecimentos cooperados a Cresol Prudentópolis, dos municípios de Prudentópolis e Guamiranga, que apresentam um total de 7.810 e 1.145 estabelecimentos agropecuários respectivamente. A população total de cooperados considerada pelo estudo é de 1.036 casos.

O Censo Agropecuário de 2006 encontrou 6.980 estabelecimentos familiares em Prudentópolis e 1.053 em Guamiranga, a agricultura familiar corresponde a $89,37 \%$ dos estabelecimentos de Prudentópolis e a 91,97\% de Guamiranga, demonstrando sua importância nestes municípios, percentual acima dos 74,8\% encontrado no território Centro-Sul - Sistema IBGE de recuperação automática(SIDRA(2012).

O tamanho da amostra, para que esta seja representativa, depende da precisão amostral determinada pela quantidade de erro, assim com uma margem de erro equivalente a $9 \%$ e coeficiente de confiança de $95 \%$, sendo o número mínimo amostral de 107 casos. A retirada dos casos seguiu algumas etapas. ${ }^{4}$ Inicialmente foi empregado o método de amostragem estratificada, seguida do método de amostragem por conglomerados, sistemática e aleatória, retirando, assim, uma amostra de 114 casos (WEBSTER, 2006; ANDERSON et al., 2007). 
As hipóteses foram trabalhadas a partir de modelos com base nas teorias apresentados na revisão bibliográfica. A hipótese estabelecida a priori, foi testada, usando da técnica estatística do teste $t$ de médias, na comparação entre grupos diferentes. $\mathrm{O}$ teste $t$ possibilitou verificar as médias dos grupos mais e menos diversificados, entendendo a diversificação no sentido de atividades.

A diversificação foi mensurada e fundamentada a partir dos levantamentos teóricos, os procedimentos classificaram os estabelecimentos em monoativos, ou seja, com rendas exclusivamente agrícolas, e pluriativos, que contam com rendas provenientes de fora da unidade de produção, tanto de base agrária como também intersetorial. Os grupos monoativos e pluriativos geraram uma variável binária com valores de zero para monoativos e um para pluriativos, o que permitiu a realização do teste $t$ de médias. As hipóteses para o teste $t$ são:

$$
\begin{aligned}
& H_{0}=\text { médias iguais; } \\
& H_{1} \neq \text { médias diferentes }
\end{aligned}
$$

As médias em relação à diversificação levaram em consideração a diversificação no sentido das estratégias de meios de vida, na comparação das médias de renda agrícola e de renda total dos monoativos e pluriativos, sendo considerado um erro estatístico de $5 \%$. Os resultados do teste $t$ de médias, somente em casos em que a média for diferente, o que comprovaria que a pluriatividade influi na renda, serão testados ainda por meio de modelos de regressão simples, para detalhar a explicação da renda em relação à característica pluriativa ou monoativa.

O cálculo da renda agrícola e da renda total segue os procedimentos metodológicos apresentados em Lima et al. (1995) e pelo Instituto Nacional de Colonização e Reforma Agrária (Incra-2011), assim em caso de aceitação de $\mathrm{H}_{1}$ pelo teste $t$ leva à aplicação do modelo de regressão simples em relação às rendas total e agrícola consideradas variáveis dependentes, e a variável binária com valores de 0 e 1 relacionadas aos estabelecimentos monoativos e pluriativos considerada variável explicativa. Foram gerados dois modelos de regressão simples, um primeiro entre a renda agrícola e a variável binária e, um segundo, com a variável binária em relação à renda total, a partir do modelo estatístico representado pela equação 1 .

$$
Y=\beta_{0}+\beta_{1} \chi_{1}+e
$$


Onde:

$Y=$ Variável dependente ou explicada;

$\beta_{0}=$ Parâmetro constante ou termo independente de variável;

$\beta_{1}=$ Inclinação de $\mathrm{Y}$ em relação à variável $\chi_{1}$;

$\chi_{1}=$ Variável explicativa do modelo ou independente; $\mathrm{e}$

$e=$ erro aleatório.

A partir do modelo estatístico, os dois modelos que estimam a influência da variável binária na formação da renda agrícola e total podem ser representados pela equação 2 .

$$
R T / R A=\beta_{0}+\beta_{1} * \operatorname{Bin}+e
$$

Onde:

$\mathrm{RT}=$ Renda Total;

$\mathrm{RA}=$ Renda Agrícola;

$\beta_{0}=$ Constante;

$\beta_{1}=$ Parâmetro desconhecido;

Bin = Variável Binária com valores de 0 para monoativos e 1 para pluriativos;

$\mathrm{e}$

$e=$ erro padrão.

A análise dos dados fez uso dos softwares IBM ${ }^{\circledR}$ SPSS ${ }^{\circledR}$ Statistics Versão 20 e Excel $^{\circledR}$ 2007. As análises serão realizadas a partir dos testes preliminares das variáveis, objetivando testar a distribuição normal, que indica a variância dos valores próximos à média. A distribuição normal significa que a variável apresenta uma distribuição continua, sendo testadas por meio dos parâmetros de Zassimetria, Zcurtose e Kolmogorov-Smirnov (HAIR, 2009).

A distribuição normal ocorre quando os valores de Zassimetria e Zcurtose não excedem um valor limite, sempre relacionado ao erro admitido, que neste caso é de 5\%, sendo assim, segundo Hair (2009), os valores obtidos com esses parâmetros não deve exceder 1,96. Já em relação ao teste de Kolmogorov-Smirnov, os parâmetros desse teste devem ser superiores a 0,05 para que a variável seja considerada normal. Assim, as hipóteses do teste de distribuição normal são:

$$
\begin{aligned}
& H_{0}=\text { distribuição normal } \\
& H_{1}=\text { distribuição não normal }
\end{aligned}
$$


No entanto, precedendo os testes de distribuição normal e propriamente à análise dos dados, Hair (2009) aponta para a necessidade da exclusão de casos tendenciosos que se afastam dos valores médios. Os outliers, como são chamados, são casos atípicos, os quais devem ser detectados e excluídos, como parâmetro são excluídos os casos que apresentarem valores acima de quatro para amostras com mais de oitenta casos, e superiores a 2,5 para amostras inferiores a oitenta casos. O Quadro 1 apresenta a análise das premissas que precede à análise dos dados.

Quadro 1 - Teste das premissas

\begin{tabular}{|l|l|c|c|c|}
\hline \multicolumn{4}{|c|}{ Teste de distribuição normal e de casos atípicos (outliers) } \\
\hline \multirow{2}{*}{ Variável } & \multirow{2}{*}{ Outliers } & \multicolumn{3}{c|}{ Testes } \\
\cline { 3 - 5 } & & Zassimetria & Zcurtose & Kolmogorov-Smirnov \\
\hline Rt_Monoativos & 1 & 1,24 & $-0,54$ & 0,096 \\
Rt_Pluriativos & 69 & 2,31 & $-0,83$ & 0,715 \\
Ra_Monoativos & 01 e 85 & 0,28 & $-0,41$ & 0,827 \\
Ra_Pluriativos & 69 e 101 & 4,31 & 2,93 & 0,630 \\
\hline
\end{tabular}

Fonte: elaborado pelo autor a partir do banco de dados de Ternoski (2013).

O Quadro 1 demonstra o resultado dos testes, indicando a exclusão dos casos atípicos, bem como a existência de distribuição normal ou não da variável. Ao todo foram excluídos quatro casos de estabelecimentos com valores tendenciosos. Em relação à renda total e renda agrícola entre os monoativos aceitou-se a hipótese $\mathrm{H}_{0}$, indicando em todos os parâmetros a distribuição normal.

Já em relação às rendas tanto agrícola como total, os parâmetros indicaram aceitação parcial da hipótese $\mathrm{H}_{0}$. Uma vez que em relação à renda total o parâmetro Zassimetria indicou distribuição não normal dos valores, e para a variável renda agrícola entre os pluriativos os valores de Zassimetria e Zcurtose apresentaram parâmetros que indicam rejeição de $\mathrm{H}_{0}$, sendo somente o teste de Kolmogorov-Smirnov que indicou aceitação da hipótese nula.

\section{Resultados e discussões}

A mensuração das rendas dos estabelecimentos rurais a partir do banco de dados de Ternoski (2013) apontou diferenças nos níveis de renda, reflexos dos mais variados fatores tanto do modo do emprego dos recursos de produção até as estratégias adotadas pelas famílias. As estratégias apontadas pela literatura revisada 
estão nas características das famílias em avançar na pluriatividade, diversificando as fontes de renda, como forma de ampliar as opções das famílias e garantir a redução das vulnerabilidades.

A partir de Long (1986) e Friedmann (1978) são apontadas as vulnerabilidades dos pequenos estabelecimentos, as quais estão relacionadas em muitos casos decorrentes das situações adversas dos mercados, uma estratégia pautada na produção de um único produto, ou então, de commodities agrícolas que eleva os riscos e as vulnerabilidades enfrentadas pelas famílias, sendo, então, minimizada está situação mediante a adoção de práticas de diversificação.

Considerando os apontamentos desenvolvidos no referencial teórico, é objeto de investigação a relação da diversificação na formação da renda agrícola e total. A análise sobre a diversificação é realizada em dois contextos; primeiro, quanto à diversificação das estratégias das famílias, no sentido da pluriatividade, em relação à formação da renda agrícola e, segundo, na relação da diversificação para a formação da renda total.

Os estabelecimentos amostrados foram classificados em monoativos e pluriativos, sendo calculado o montante de renda agrícola e total, buscando a relação das médias dessas rendas com a característica pluriativa ou monoativa. $\mathrm{O}$ teste $t$ de médias indicou as diferenças nas médias, conforme apresentado no Quadro 2.

Quadro 2 - Teste $t$ sobre as médias dos grupos amostrados mais e menos diversificados

\begin{tabular}{|c|c|c|c|c|c|}
\hline \multicolumn{7}{|c|}{ Teste $t$ de médias } \\
\cline { 1 - 3 } Variáveis comparadas & \multicolumn{2}{c|}{ Médias comparadas } & \multirow{2}{*}{$\begin{array}{c}\text { Hipótese con- } \\
\text { firmada }\end{array}$} \\
\cline { 1 - 3 } Variável 1 & Variável 2 & Média variável 1 & Média variável 2 & & $\mathrm{H}_{1}$ \\
Ra_Monoativos & Ra_Pluriativos & $5.534,30$ & $14.513,91$ & 0,003 & $\mathrm{H}_{1}$ \\
\hline
\end{tabular}

Fonte: elaborado pelo autor.

O teste $t$ de amostras independentes considerou, conforme apresentado nos procedimentos metodológicos, um nível de significância estatística de 5\%, desta forma os valores do parâmetro que excederem 0,05 indicam a aceitação da hipótese nula, ou seja, médias iguais. Os resultados conforme apresentados pelo Quadro 2 demonstram que o teste $t$ de médias indica ao nível de significância estatística de $5 \%$ à existência de médias diferentes tanto da renda agrícola como da renda total entre pluriativos e monoativos.

O valor médio da renda agrícola dos monoativos corresponde a $38,13 \%$ do valor da renda agrícola recebida pelos pluriativos. Já em relação à renda total, o 
percentual da renda dos monoativos aproxima-se dos pluriativos, mas ainda é menor e corresponde a aproximadamente $72,72 \%$ do valor recebido pelos pluriativos.

A comprovação da hipótese de que as médias das rendas agrícola e total dos pluriativos e monoativos são diferentes requer novos testes para validar os resultados, assim faz-se necessário gerar o modelo de regressão no sentido de verificar a explicação dessas rendas pela característica pluriativa ou monoativa. No entanto, precedendo ao modelo de regressão torna-se imprescindível compreender os valores que formam essas rendas.

A mensuração dos níveis de renda agrícola e total considera a característica monoativa e pluriativa. Entendendo a monoatividade, o estabelecimento obtém rendas exclusivamente agrícolas e de dentro da unidade de produção, e pluriativos, para os casos em que ocorre o recebimento de rendas provenientes de fora dos estabelecimentos, tanto de origem agrícola como não agrícola.

A pluriatividade conforme apontada no referencial teórico está ligada à expansão das oportunidades de acesso a diferentes fontes de renda, como também nos estágios iniciais da entrada do estabelecimento na pluriatividade podem ser relacionados a uma estratégia de sobrevivência. Os dados apresentados nesta pesquisa empírica demonstram a existência de rendas mais elevadas entre os pluriativos, evidenciando que estabelecimentos que diversificam suas estratégias obtêm receitas mais elevadas.

As análises desenvolvidas levam em conta 110 casos de estabelecimentos na análise da renda agrícola e 112 casos para a análise da renda total, dada uma amostra de 114 estabelecimentos. A redução de quatro estabelecimentos na análise da renda agrícola, e dois para a renda total decorrem da exclusão dos outliers conforme detalhado na metodologia.

Os testes de distribuição normal indicaram que entre os monoativos ocorre distribuição normal, ou seja, aceitação de $\mathrm{H}_{0}$ em todos os parâmetros, já para as rendas agrícola e total dos pluriativos a distribuição normal foi parcialmente aceita dado em que algum parâmetro tenha apresentado valores que indicam a rejeição da hipótese nula. No entanto, os testes de observações atípicas indicam que não existem valores tendenciosos.

Conforme apresentado no Quadro 2 foi possível observar a existência de médias diferentes entre pluriativos e monoativos, tanto de rendas agrícolas como na renda total, a análise sobre as rendas dos pluriativos deve ser feita com cautela, uma vez da indicação de não existência de distribuição normal dos valores. A Tabela 1 apresenta a descrição dos dados observados. 
Tabela 1 - Comparação das variáveis de renda agrícola $(\mathrm{Ra})$ e renda total $(\mathrm{Rt})$ entre monoativos e pluriativos para a safra 2011/2012 (valores em R\$)

\begin{tabular}{l|r|r|r|r|r|r}
\hline \multicolumn{7}{c}{ Estatísticas descritivas } \\
\hline \multicolumn{1}{c|}{ Variáveis } & \multicolumn{1}{c|}{ N } & \multicolumn{1}{c}{ Mínimo } & \multicolumn{1}{c}{ Máximo } & \multicolumn{1}{c}{ Soma } & \multicolumn{1}{c}{$X$} & \multicolumn{1}{c}{$S$} \\
\hline Ra_Monoativos & 19 & $-11.398,08$ & $25.391,42$ & $105.151,88$ & $5.534,31$ & $9.423,58$ \\
Ra_Pluriativos & 91 & $-28.435,28$ & $73.382,65$ & $1.320 .765,91$ & $14.513,91$ & $18.074,86$ \\
Rt_Monoativos & 20 & $-2.411,49$ & $41.179,17$ & $380.825,05$ & $19.041,25$ & $11.251,70$ \\
Rt_Pluriativos & 92 & $-19.349,28$ & $80.143,32$ & $2.408 .911,79$ & $26.183,82$ & $18.900,29$ \\
\hline
\end{tabular}

Fonte: elaborado pelo autor.

Os dados da Tabela 1 apresentam as variações nas rendas e demonstram maiores níveis de renda entre os pluriativos. Verifica-se que, no acumulado, a renda agrícola dos monoativos corresponde a 7,96\% do montante de renda agrícola gerado pelos pluriativos, valor esse explicado pelo número de casos, mas que na média ainda corresponde a $38,12 \%$ da renda agrícola média verificada no grupo de pluriativos.

Em relação à renda total, o grupo de estabelecimentos pluriativos também foi superior aos monoativos, totalizando 92 pluriativos contra vinte estabelecimentos monoativos, o que fez com que o montante gerado nos estabelecimentos monoativos correspondesse a apenas $15,81 \%$ do montante total gerado nos estabelecimentos pluriativos. No entanto, conforme já apresentado no Quadro 2 e exposto novamente na Tabela 1 a renda total dos monoativos aproximou-se da renda total média dos pluriativos, correspondendo a $72,72 \%$ do recebimento médio dos pluriativos.

Os valores médios obtidos com a renda total e agrícola indicam a pluriatividade como positiva na formação da renda. Os apontamentos de Long (1986) chamam atenção para o aumento do número de agricultores que buscam fora do estabelecimento fontes de renda, e está tendência foi comprovada pelo número superior de estabelecimentos pluriativos. A pluriatividade é um fator positivo para a elevação da renda.

Essa característica é importante para a redução das vulnerabilidades ao inserir novas possibilidades nas estratégias dos agricultores, reduzindo, assim, os riscos das carteiras mais concentradas. Ellis (2000) aponta, neste sentido, a necessidade de diversificar as estratégias adotadas, como forma de reduzir a pobreza e as vulnerabilidades enfrentadas pelas famílias, e elevar as rendas a partir das oportunidades encontradas na pluriatividade.

A teoria da commoditização apresentada em Long (1986) e os efeitos dos mercados sobre a agricultura familiar em Friedmann (1978) podem ser relacionados 
aos resultados verificados. A característica monoativa limita o estabelecimento a rendas exclusivamente agrícola e de dentro da propriedade familiar, assim os efeitos adversos dos mercados são sentidos em maior proporção entre os monoativos, uma vez que os pluriativos contam com outras fontes de rendas além das atividades comuns da agricultura. Os Gráficos 1 e 2 apresentam o detalhamento das rendas para cada grupo.

Gráfico 1 - Tipificação dos estabelecimentos rurais amostrados em monoativos e pluriativos de acordo com a renda agrícola: safra 2011/2012

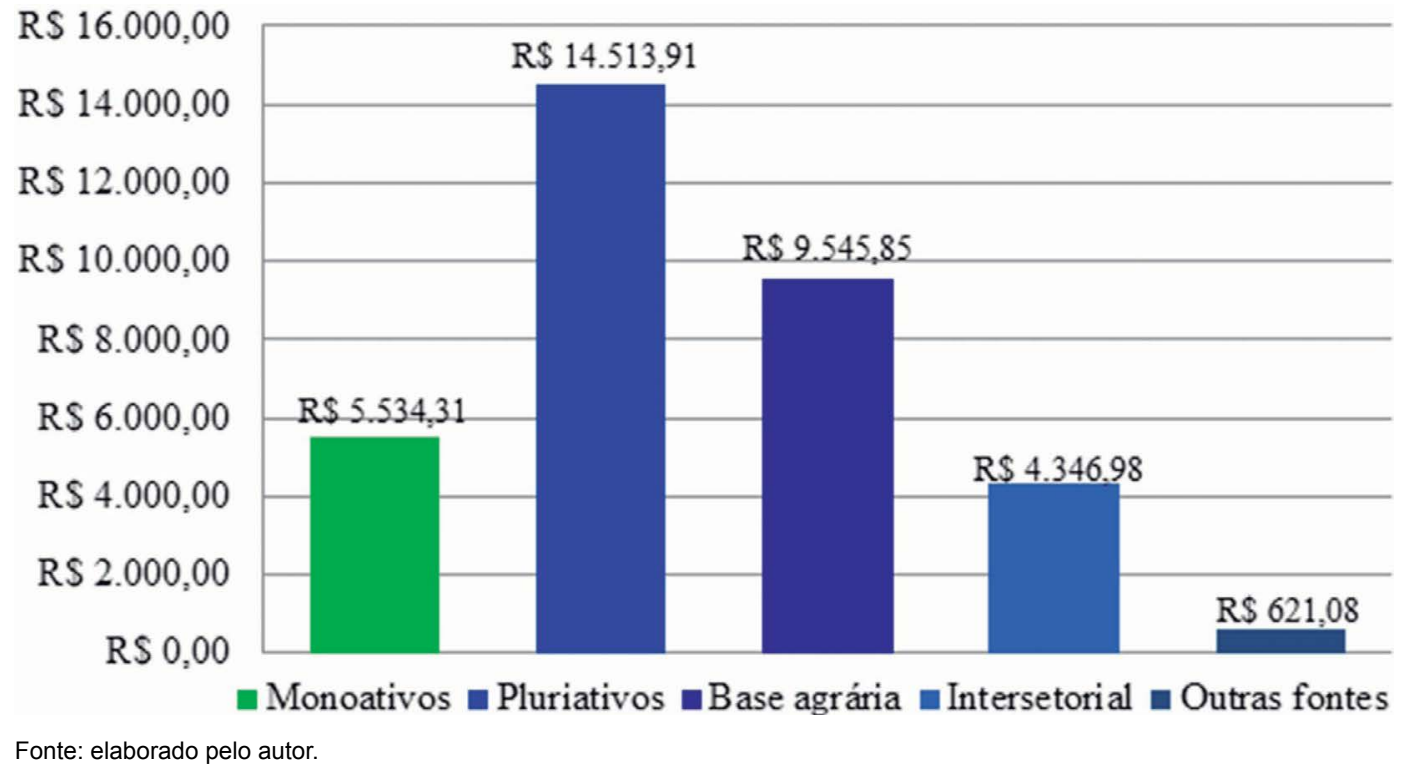

A partir da tipificação dos estabelecimentos é possível, por meio do Gráfico 1, verificar as médias com a renda agrícola. Entre os pluriativos a média da Ra foi de $R \$ 14.513,91$, enquanto que entre o grupo de monoativos foi de $R \$ 5.534,31$. No contexto da pluriatividade, a renda é formada em maior percentual por estratégias de reprodução de base agrária, com $65,77 \%$, representada nos trabalhos agrícolas fora da unidade de produção. As estratégias intersetoriais, que são as atividades não agrícolas, representam um peso de $29,95 \%$ e as outras formas $4,28 \%$, na relação com a renda agrícola.

Em relação ao Gráfico 2, verifica-se que a média da renda total dos pluriativos foi de $R \$ 26.183,37$, enquanto que entre o grupo de monoativos a $R t$ foi de $R \$$ 19.041,25. Dentro da formação da renda total na pluriatividade, as estratégias de renda de base agrária, conforme Gráfico 2, correspondem a 53,03\% do montante de 
recursos gerados com a pluriatividade, $43,65 \%$ nas estratégias intersetoriais para a formação da renda, e em $4,32 \%$ com outras estratégias de reprodução.

Gráfico 2 - Tipificação dos estabelecimentos rurais amostrados em monoativos e pluriativos e a Rt: safra 2011/2012

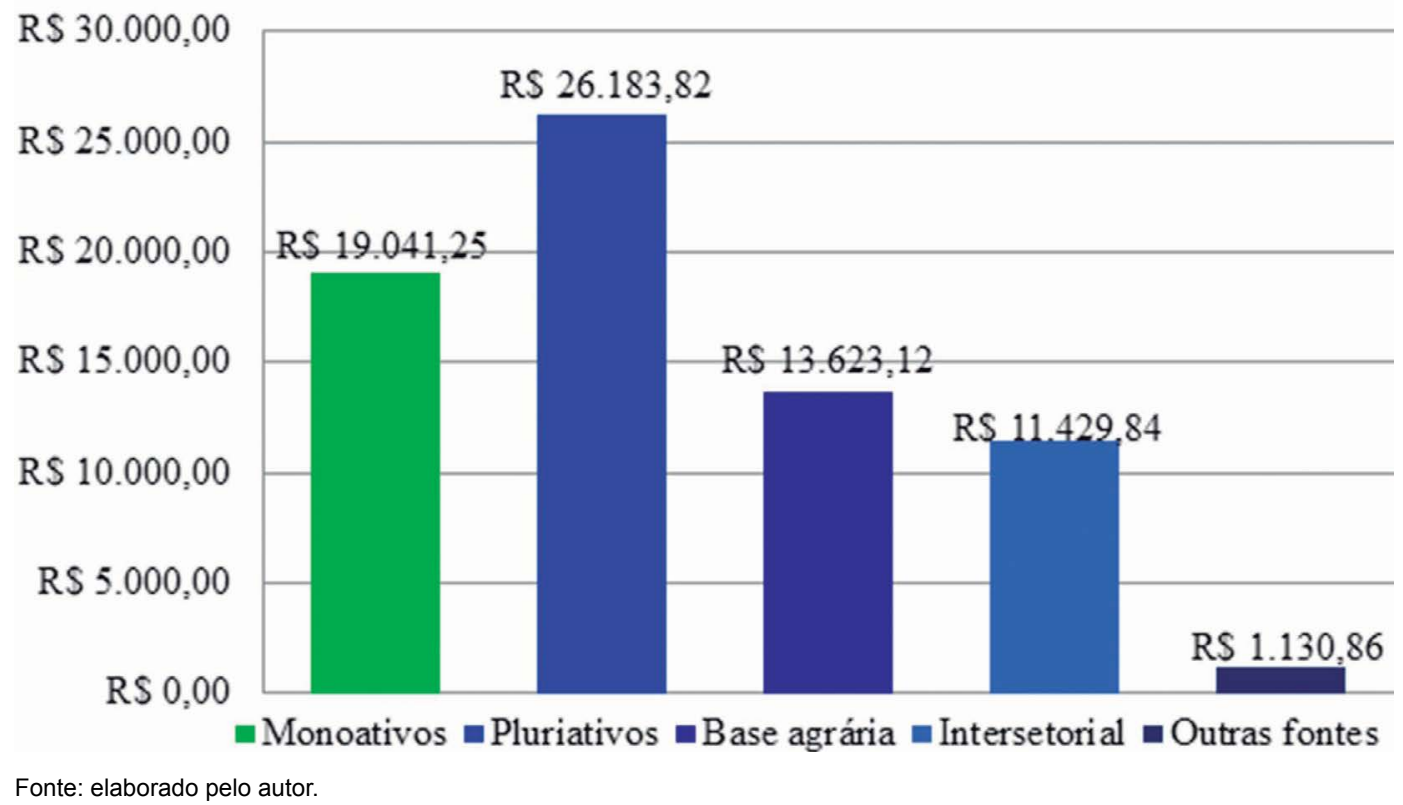

As verificações corroboram com o referencial desenvolvido, uma vez que a diversificação das fontes de renda amplia as possibilidades de recebimentos, eleva 0 número de atividades desenvolvidas, reflete na melhoria da renda total e agrícola, e reduz as vulnerabilidades e os riscos dos mercados. Os resultados levam à aceitação das hipóteses estabelecidas, mas sua verificação requer testes mais detalhados no sentido de comprovar a explicação da renda pela característica pluriativa ou monoativa.

Para tanto, é necessário aplicar o modelo de regressão simples, considerando as variáveis explicadas, renda agrícola e a renda total, e como preditora, a variável binária que considera a pluriatividade e a monoatividade, conforme descrito nos procedimentos metodológicos. A regressão será aplicada as duas rendas, gerando, portanto, dois modelos, visto que o teste $t$ apresentou a existência de médias diferentes tanto para a renda agrícola como para a total. A Tabela 2 apresenta a correlação entre as variáveis. 
Tabela 2 - Correlação entre a variável explicada (Rt e Ra) e a variável binária explicativa

\begin{tabular}{l|l|r|r|r|r}
\hline \multicolumn{6}{c}{ Correlação entre as rendas e a característica monoativa e pluriativa } \\
\hline \multirow{3}{*}{ RT / RA } & Correlação de Pearson & \multicolumn{1}{c}{ Ra } & \multicolumn{1}{c}{ Bin } & \multicolumn{1}{c}{$R t$} & \multicolumn{1}{c}{ Bin } \\
\hline & Sig.(2extremidades) & & $0,198^{*}$ & 1 & 0,153 \\
& N & 110 & 0,038 & & 0,107 \\
& & & 110 & 112 & 112 \\
\hline
\end{tabular}

Legenda: * A correlação é significativa ao nível de $5 \%$ (duas extremidades).

Fonte: dados da pesquisa.

Os dados apresentados na Tabela 2 indicam a existência de correlação ao nível de significância estatística de 5\% entre a variável dependente renda agrícola e a variável binária explicativa. Para a variável renda total foi verificada correlação com a variável preditora binária, no entanto essa correlação está acima do nível de significância estatística considerada por este estudo. Verificada a correlação, a próxima etapa foi a aplicação do modelo descrito na metodologia, e na Tabela 3 verifica-se os resultados obtidos.

Tabela 3 - Coeficientes estatísticos para a variável binária em relação às variáveis dependentes: renda agrícola e total

\begin{tabular}{|c|c|c|c|c|c|c|c|c|}
\hline \multicolumn{9}{|c|}{ Coeficientes } \\
\hline & \multirow[t]{2}{*}{ Modelo } & \multicolumn{2}{|c|}{ Coeficientes não padronizados } & \multirow{2}{*}{$\begin{array}{c}\begin{array}{c}\text { Coeficientes } \\
\text { padronizados }\end{array} \\
\text { Beta }\end{array}$} & \multirow[t]{2}{*}{$t$} & \multirow[t]{2}{*}{$P$} & \multicolumn{2}{|c|}{$\begin{array}{l}\text { Estatísticas de } \\
\text { colinearidade }\end{array}$} \\
\hline & & B & Erro padrão & & & & Tolerância & VIF \\
\hline \multirow[t]{2}{*}{1} & (Constante) & $5.534,31$ & $3.886,89$ & & 1,424 & 0,15 & & \\
\hline & $\operatorname{Bin}^{a}$ & $8.979,60$ & $4.273,44$ & 0,198 & 2,101 & 0,03 & 1,00 & 1,00 \\
\hline \multirow[t]{2}{*}{2} & (Constante) & $19.041,25$ & $3.983,63$ & & 4,780 & 0,00 & & \\
\hline & $\operatorname{Bin}^{b}$ & $7.142,57$ & $4.395,36$ & 0,153 & 1,625 & 0,10 & 1,00 & 1,00 \\
\hline
\end{tabular}

a. Variável dependente: Ra; b. Variável dependente: Rt.

Fonte: dados da pesquisa.

Os dados da Tabela 3 demonstram que para a variável dependente renda agrícola a variável binária preditora explica a formação da renda ao nível de significância estatística de 5\%. A alteração da condição de monoativo para pluriativo eleva a renda agrícola, conforme demonstrou os resultados do modelo em $\mathrm{R} \$$ 8.979,60.

Em relação à renda total foi verificado que se tornar monoativo elevaria a renda em $\mathrm{R} \$ 7.142,57$, no entanto o resultado em relação à renda total não é valido ao nível de significância estabelecido por este estudo, uma vez que o erro apresentado foi de $10,7 \%$. Aplicando-se os dados ao modelo 2 apresentado nos procedimentos metodológicos, o modelo fica resumido pela expressão 3 . 


$$
R a=5.534,31+8.979,60 B i n
$$

Vale destacar que o modelo que considera a renda total não será detalhado, uma vez que não apresentou nível de significância estatística dentro dos padrões estabelecidos, sendo excluído por apresentar nível de significância de 0,107. A Tabela 4 apresenta os demais valores do modelo de regressão simples.

Tabela 4 - Coeficientes estatísticos para a variável binária independente em relação às variáveis explicadas (Ra e Rt)

\begin{tabular}{|c|c|c|c|c|c|c|c|c|}
\hline \multicolumn{9}{|c|}{ Coeficientes variáveis independentes } \\
\hline \multicolumn{5}{|c|}{ Anova } & \multicolumn{4}{|c|}{ Resumo do modelo } \\
\hline & Modelo & Média quadrados & $\mathrm{F}$ & $\mathrm{p}$ & $\mathrm{R}$ & $\mathrm{R}^{2}$ & $\mathrm{R}^{2}$ ajustado & $\begin{array}{l}\text { Erro padrão } \\
\text { estimativa }\end{array}$ \\
\hline \multirow[t]{2}{*}{$1^{\mathrm{a}}$} & Regressão & 1267407973,82 & 4,415 & $0,038^{b}$ & $0,198^{b}$ & 0,039 & 0,030 & 16942,58 \\
\hline & Residual & 287051084,13 & & & & & & \\
\hline \multirow[t]{2}{*}{$2^{c}$} & Regressão & 838125309,28 & 2,641 & $0,107^{b}$ & $0,153^{\mathrm{b}}$ & 0,023 & 0,015 & 17815,34 \\
\hline & Residual & 317386460,00 & & & & & & \\
\hline
\end{tabular}

a. Variável dependente: Ra; b. Previsores: (Constante), Bin; c. Variável dependente: Rt. Fonte: dados da pesquisa.

O modelo que considera a variável renda agrícola explicada pelos preditores representados na variável binária apresentou conforme exposto na Tabela 4 coeficiente de correlação $\mathrm{R}$ de $19,8 \%$. Já o coeficiente de determinação $\mathrm{R}^{2}$ demonstra que a variável binária explica $3 \%$ da variância da variável dependente renda agrícola em torno de sua média, percentual muito baixo indicando a existência de outras variáveis que explicariam a formação da renda agrícola. Esses resultados consideram um nível de significância estatística de $5 \%$.

Em relação à renda total, a variável binária explica 1,5\% da variância da renda total em torno de sua média, no entanto, os resultados não apresentam nível de significância estatística dentro dos padrões admitidos pelo estudo. As constatações apresentaram percentuais de explicação com grandezas numéricas baixas, indicando a existência de outras variáveis exógenas na explicação da renda total, como as variáveis apresentadas em um estudo de Ternoski e Perondi (2013), ${ }^{5}$ que indicam que a explicação das rendas pela característica pluriativa é baixa, mesmo existindo médias diferentes testadas pelo teste $t$.

O nível de significância estatística é superior ao erro admitido e apresentado no modelo que considerou a renda total, bem como a distribuição não normal dos dados, evidencia a necessidade de dados de séries temporais maiores, no sentido 
de corrigir essas falhas, podendo então resultar em parâmetros dentro dos níveis aceitáveis. Esse fator demanda estudos futuros a respeito dessa relação.

\section{Considerações finais}

As estratégias de meios de vida é uma das características marcante das famílias de pequenos agricultores do espaço rural brasileiro. A diversidade encontrada na agricultura familiar é um laboratório para inferências, principalmente no repensar das políticas públicas para o desenvolvimento rural. $\mathrm{O}$ próprio conceito de agricultura familiar evoluiu e continua se alterando junto com as relações no meio social em que a agricultura familiar está inserida.

Pensar agricultura familiar é considerar as inúmeras estratégias, tanto de sobrevivência quanto de acumulação de capital, estratégias estas que agricultores adotam no sentido de acessar maiores níveis de renda. Muitos são privados das condições mínimas viáveis para sua subsistência, as privações podem ocorrer tanto pela falta de capacidades do indivíduo ou da família, como também das condições adversas do meio, desde as pressões mercadológicas, climáticas ou então insuficiência ou propriamente falta de requisitos para acessar as políticas públicas.

As políticas públicas são pensadas no sentido de reduzir as ineficiências da agricultura, como também de promover o acesso das populações mais carentes as condições minimamente viáveis de vida. Refletir sobre políticas públicas para o meio rural é considerar os mecanismos capazes de reduzir as vulnerabilidades do contexto no qual o agricultor esta inserido. As vulnerabilidades são apresentadas de diferentes formas e este estudo considerou primordialmente as vulnerabilidades dos mercados e os riscos da produção de commodities ou da especialização, pautando-se nas estratégias de renda.

As questões foram centradas na verificação da existência de correlação positiva entre a diversificação dos meios de vida e a formação da renda. As análises cumpriram com o objetivo proposto, analisando a diversificação e a composição da renda agrícola e total.

As inferências realizadas permitiram verificar a partir de uma variável binária, considerando a característica monoativa e pluriativa dos estabelecimentos amostrados, a relação com a formação da renda total e agrícola. Por meio do teste $t$ de médias foi possível constatar a existência de médias diferentes entre ambos os grupos, tanto da renda agrícola como da renda total, além do que as médias são mais elevadas para o grupo de pluriativos. 
Verificou-se que o valor médio da renda agrícola dos monoativos era de apenas $38,13 \%$ do valor médio recebido pelos pluriativos, percentual que se aproximava para a renda total, mas os níveis ainda continuam menores para os monoativos. A renda total dos monoativos foi de $72,72 \%$ do valor médio recebido pelos pluriativos, o teste $t$ de médias considerou um nível de significância estatística de $5 \%$.

Constatada a diferença das médias, foi possível gerar um modelo de regressão simples, relacionando as variáveis dependentes renda total e renda agrícola com a variável binária considerada explicativa. Assim, dois modelos foram gerados, apontando a relação dessa variável na determinação e formação da renda.

O modelo que considerou a renda agrícola como dependente e a variável binária como preditora, apontou que a condição de sair da monoatividade e tornar-se pluriativo gera uma elevação da renda de $\mathrm{R} \$ 8.979,60$. No entanto, a variável binária explica, ao nível de significância estatística de 5\%, apenas $3 \%$ da variância renda agrícola em torno de sua média. Percentual esse muito baixo, indicando a existência de outras variáveis relacionadas à explicação da formação da renda agrícola.

Em relação à renda total os resultados não foram significativos ao nível estabelecido por este estudo, indicaram que a condição de tornar-se pluriativo gera uma elevação de $\mathrm{R} \$ 7.142,57$ na renda total, explicando 1,5\% da variância da renda total em torno de sua média. Mas os resultados para a renda total não são válidos ao nível de significância de 5\% estabelecida por este estudo, uma vez que o erro encontrado foi de $10,7 \%$.

As inferências permitiram confirmar a hipótese de que a diversificação representada na pluriatividade esta relacionada ao maior nível de renda agrícola e total, confirmada pelo teste $t$, mas sem ter a explicação da formação da renda total pela pluriatividade verificada no modelo de regressão simples.

A literatura revisada aponta uma diversidade de condições que levam os agricultores a tornarem-se pluriativos. Tanto como uma estratégia de sobrevivência, como também de acumulação de capital, e uma possível explicação que levou a variável binária a não apresentar influência na determinação da renda total pode estar relacionada aos muitos estabelecimentos que adotam temporariamente a estratégia pluriativa como forma de sobrevivência, e não como uma forma de acumulação de capital.

A ampla literatura apresenta esta tendência como relacionada a trabalhos mal pagos, o que pode influenciar na formação da renda. A partir do instante em que os estabelecimentos adotam a diversificação como uma estratégia de acumulação de capital, os reflexos na renda são constantes e não temporários, o que poderia explicar a determinação da renda. 
As práticas de diversificação elevam as opções e as fontes de renda, e, conforme indicado na literatura pesquisada, espalham os riscos sobre as várias fontes. As oscilações nos mercados agrícolas são sentidas em menor proporção pelas famílias pluriativas que contam com outras fontes de receitas, reduzindo a vulnerabilidade e os riscos enfrentados.

A diversificação dos meios de vida, expressa na pluriatividade, deve ser inserida na agenda política como uma estratégia para o desenvolvimento rural, incentivar tal prática pode reduzir as vulnerabilidades, promovendo o acesso do agricultor familiar a um nível de renda mais elevado. Esta investigação abre um leque para futuras pesquisas, tanto ao considerar um recorte temporal maior, como também buscar realizar inferências, separando estabelecimentos pluriativos que adotem essa estratégia como uma estratégia de acumulação e de sobrevivência, buscando relacionar esses casos com a formação da renda. 


\title{
Strategies of diversification of means of life and the formation of income: an empirical analysis on the cooperative of family farms Cresol Prudentópolis
}

\begin{abstract}
The income strategies guided by the diversification of livelihoods are associated with the formation of income properties. So the theory that guides this study focuses on the different strategies of livelihoods in rural, especially in relation to the theme of pluriativity. As a hypothesis it is assumed that the farmer with more diversified source of income has a lower vulnerability and a higher overall and farm income. The methodology consists in explanatory research, quantitative character, from the use of sampling techniques and statistical methods (t test and regression). As a result, it was found that: (1) diversification of livelihoods, expressed in pluriativity, allows establishments, according to the t test, higher levels of income; (2) The binary predictor variable, through the simple regression model, presented explanation of the dependent variable farm income, but does not explain the dependent variable total income. We conclude that the pluriativity is linked to higher levels of income, but without explaining the formation of total income.
\end{abstract}

Keywords: Pluriactive. Family farming. Typing. Income diversification. Monoactive.

\section{Estrategias de diversificación de medios de vida y la formación de ingresos: un análisis empírico de la cooperativa de agricultura familiar Cresol Prudentópolis.}

\section{Resumen}

Las estrategias de renta guiadas por la diversificación de los medios de vida están asociados con la formación de propiedades de renta. Así que la teoría que guía este estudio se centra en las diferentes estrategias de medios de vida en las zonas rurales, especialmente en relación con el tema de la plurinacionalidad. Como hipótesis se supone que el agricultor con la fuente más diversificada de ingresos tiene una menor vulnerabilidad y un ingreso total y agrícola superior. La metodología consiste en la investigación explicativa, carácter cuantitativo, de la utilización de técnicas de muestreo y los métodos estadísticos ( $\mathrm{t}$ test y regresión). Como resultado, se encontró que: (1) la diversificación de los medios de vida, expresada en la pluriativity, permite establecimientos, de acuerdo con la prueba de la $t$, los niveles más altos de ingresos; (2) La variable de predicción binaria, a través del modelo de regresión simple, presenta una explicación de la renta agrícola variable dependiente, pero no explica el ingreso total de la variable dependiente. Llegamos a la conclusión de que la pluriativity está vinculada la mayores niveles de ingreso, pero sin explicar la formación de la renta total.

Palabras clave: Pluriactivas. Agricultura familiar. Clasificación. La diversificación de los ingresos. Monoactive. 


\section{Notas}

1 Versão preliminar apresentada no III Semana de Integração Ensino, Pesquisa e Extensão (Siepe), Universidade Estadual do Centro-Oeste (Unicentro) 2013.

2 O Moshav descrito em Sofer (2001) é uma espécie de assentamento com características cooperativistas.

3 Lewis estima que os salários urbanos sejam estabelecidos em torno de $30 \%$ acima desse nível de subsistência agrícola, ver em Souza (2012).

4 O detalhamento dos procedimentos está descrito em Ternoski (2013).

5 Ternoski e Perondi (2013) encontraram por meio de modelos de regressão multivariada, explicação da variância da variável renda total de $34 \%$ pelo capital financeiro e humano. O banco de dados utilizado por esses autores é o mesmo que está sendo empregado neste estudo.

\section{Referências}

ANDERSON, David Ray et al. Estatística aplicada à administração e economia. 2. ed. São Paulo: Thomson Learning, 2007.

BARLETT Peggy F. Rolnicy dwuzawodowi: zachowanie gospodarstwa czy wiejskiego stylu życia? In: Krzysztof Gorlach (Ed.). Socjologia wsi w Ameryce Północnej, Toruń, UMK. 1998 BAUMEL, Adriana; BASSO, Luiz Carlos. Agricultura familiar e a sustentabilidade da pequena propriedade rural. In: CAMARGO, Gisele; CAMARGO FILHO, Maurício; FÁVARO, Jorge Luiz (Orgs.). Experiências em desenvolvimento sustentável e agricultura familiar. Guarapuava: Ed. Unicentro, 2004.

BEUREN, Ilse Maria. (Org.). Como elaborar trabalhos monográficos em contabilidade: teoria e prática. São Paulo: Editora Atlas, 2004.

BLAD, Marta. Pluriactivity of farming families - old phenomenon in new times. In: European Rural Development Network Studies. Rural Areas and Development., p. 155-165, v. 7, 2010. Disponível em: <http://ageconsearch.umn.edu/bitstream/139799/2/ vol.\%207_12.pdf. Acesso em: 23 dez. 2013.

BOWLER, I.; CLARK, G., CROCKETT, A.; ILBERY, B.; SHAW, A. The development of alternative farm enterprises: A study of family labour farms in the Northern Pennines of England. Journal of Rural studies, New York, v. 12, n. 3, p. 285-295, Jul. 1996.

DURAND, Guy;HUYLENBROECK, Guido van. Multifunctionality and rural development: a general framework. In: Guido van Huylenbroeck and Guy Durand. Multifunctional agriculture. A new paradigm for European Agriculture and Rural Development. Ashgate Publishing Company, USA, 2003.

ELLIS, Frank. Rural livelihoods and diversity in developing countries. Oxford: Oxford University, 2000.

ESTRADA, Eduardo Moyano. Agricultura familiar, pluriatividade e desenvolvimento rural no Sul do Brasil. In: Revista Estudos Sociedade e Agricultura, Rio de Janeiro, v. 1, n. 20, p. 199-202, abr. 2003.

European Commission. Other gainful activities: pluriactivity and farm diversification in the EU 27. LTB D 17488, Brussels. 2008. 
FRIEDMANN, H. World market, state and family: social bases of household production in the era of wage labour. Comparative Studies in Society an History, Cambridge, v. 20, n. 4, p. 545-586, Oct. 1978.

FULLER, A. M. From part-time farming to pluriactivity: a decade change in Europe. Journal of Rural Studies, New York, v. 6, n. 4, p. 361-375, Oct. 1990.

GILAD, B.;LEVINE, P. A behavioral model of entrepreneurial supply. Journal of Small Business Management, Canadá, v. 24, n. 4, p. 45-54, Oct. 1986.

HAIR et al. Análise multivariada de dados. 6 ed. Porto Alegre: Bookman, 2009.

IBGE - Instituto Brasileiro de Geografia e Estatística. IBGE/CIDAES. Disponível em: <http://www.ibge.gov.br/home>. Acesso em: 14 abr. 2012.

INCRA - Instituto Nacional de Colonização e Reforma Agrária. Análise Diagnóstico de Sistemas Agrários: guia metodológico. 2011. Disponível em: <http://www.incra. gov.br/index. $\mathrm{php} /$ reforma-agraria-2/analise-balanco-e-diagnosticos/file/57-guia-metodologico-analise-diagnostico-de-sistemas-agrarios>. Acesso em: 3 set. 2012.

IPARDES - Instituto Paranaense de Desenvolvimento Econômico e Social. Diagnóstico socioeconômico do Território Centro-Sul. Curitiba: Ipardes, 2007.

Instituto Paranaense de Desenvolvimento Econômico e Social. Caderno Estatístico Município de Prudentópolis. Curitiba: Ipardes, 2012a.

. Instituto Paranaense de Desenvolvimento Econômico e Social. Caderno Estatístico Município de Guamiranga. Curitiba: Ipardes, 2012b.

JERVELL, Anne Moxnes. Changing Patterns of Family Farming and Pluriactivity. European Society for Rural Sociology. In: Sociologia Ruralis, v. 39, n. 1, 1999. Disponível em: $<$ http://www.researchgate.net/publication/229568934_Changing_ Patterns_of_Family_ Farming_and_Pluriactivity/file/d912f50852c7b5ada6.pdf>. Acesso em: 23 dez. 2013.

KAGEYAMA, A. As múltiplas fontes de renda das famílias agrícolas brasileiras. Agricultura em São Paulo, São Paulo, v. 48. n. 2, p. 57-69, jul./dez. 2001.

KNICKEL Karlheinz; PLOEG Jan Douwe Van Der; RENTING, Henk. Multifunktionalitat der Landwirtschaft und des landlichen Raumes: Welche Funktionen sind eigentlich gemeint und wie sind deren Einkommens - und Beschaftigungspotenziale einzuschatzen? GEWISOLA - Tagung 2003 an der Universitata Hohenheim, Stuttgart. 2003.

LIMA. A. J. P. et al. Administração da Unidade de Produção Familiar: modalidade de trabalhos com agricultores. Ijuí: Unijuí, 1995.

LONG, Norman. Commoditization: thesis and antithesis. In: LONG, Norman; PLOEG, Jan Douwe van der; CURTIN, Chris; BOX, Louk. The commoditization debate: labour process, strategy and social network. Netherlands Agricultural University of Wagening, 1986. p. 8-24.

LOUGHREY, Jason; DONNELLAN, Trevor; HENNESSY, Thia and HANRAHAN, Kevin. The Role of Pluriactivity in Farm Exit and Labour Supply Decisions. In: Factor Markets Working Paper. n. 67, Aug. 2013. Disponível em: <http://www.ceps. be/book/role-pluriactivity-farm-exit-and-labour-supply-decisions>. Acesso em: 23 dez. 2013.

MARX, Karl. O Capital, crítica da economia política. Trad. de Regis Barbosa e Flávio R. Kothe. São Paulo: Editora Nova Cultural, v. 1, 1996. 
MATOS, Orlando Carneiro de. Econometria básica: teoria e aplicações. 2. ed. São Paulo: Atlas, 1997.

MCNALLY, S. Farm diversification in England and Wales-what can we learn from the farm business survey? Journal of Rural Studies, New York, v. 17, n. 2, p. 247-257, Oct. 2001.

MERRIAN, S. B. Case study research in education: a qualitative approach. São Francisco: JosseyBass, 1988.

PERONDI, M. A.; SCHNEIDER, S. Bases teóricas da abordagem de diversificação dos meios de vida. Revista Redes, Santa Cruz do Sul, v. 17, n. 2, p. 117-135, amio/ago. 2012.

POLANYI, Karl. Nossa obsoleta mentalidade mercantil. In: Revista Trimestral de História das Idéias Porto- Portugal, v. 1, n. 1, p. 7-20, jan./dez. 1977.

RICHARDSON, R. J. Pesquisa social: métodos e técnicas. 3. ed. São Paulo: Atlas, 2008.

SCHNEIDER, S. A pluriatividade na agricultura familiar. Porto Alegre: Editora da UFRGS, 2003.

- Reflexões sobre diversidade e diversificação da agricultura, formas familiares e desenvolvimento rural. RURIS, Campinas-SP, v. 4, n. 1, p. 85-131, mar. 2010.

SIDRA - Sistema IBGE de Recuperação Automática. Censo Agropecuário 2006. Disponível em: <http://www.sidra.ibge.gov.br/bda/pesquisas/ca/default.asp>. Acesso em: 26 jun. 2012.

SILVA, Ranmuthumalie de, KODITHUWAKKU, Sarath S. Pluriactivity, entrepreneurship and socio-economic success of rural households. In: Manchester Business School working paper, n. 596. 2010. Disponível em: <http://www. econstor.eu/bitstream/10419/50729/1/65691 9760.pdf>. Acesso em: $23 \mathrm{dez} .2013$.

SOFER. Michael. Pluriactivity in the Moshav: family farming in Israel. In: Journal of Rural Studies, v. 17, p. 363-375, 2001. Disponível em: <http://www.xn--5dbfeoa0hef.org.il/Portals/0/Documents/articles/sofer\%20-\%20pluriactivity\%20-\%20jrs.pdf>. Acesso em: $23 \mathrm{dez}$. 2013.

SOUZA, Nali de Jesus de. Desenvolvimento Econômico. 6. ed. Rev. Editora Atlas: São Paulo, 2012.

TERNOSKI. Simão. Estratégias de melhoria da renda da agricultura familiar: análise a partir da base social da CRESOL/Prudentópolis. Dissertação (Mestrado em Desenvolvimento Regional) - Programa de Pós-Graduação em Desenvolvimento Regional. Universidade Tecnológica Federal do Paraná - UTFPR. Pato Branco, 2013. Disponível em: <http:// www.utfpr.edu.br/patobranco/estrutura-universitaria/diretorias/dirppg/pos-graduacao/ mestrados/ppgdr2/discentes/PB_PPGDR_M_TernoskiSimo_2013.pdf.pdf $>$. Acesso em: 23 dez. 2013.

TERNOSKI, Simão e PERONDI, Miguel Ângelo. Variáveis que explicam a Renda Familiar dos Cooperados de Crédito Rural nos Municípios de Guamiranga e Prudentópolis no Paraná. In: CONGRESSO DA SOCIEDADE BRASILEIRA DE ECONOMIA, ADMINISTRAÇÃO E SOCIOLOGIA RURAL - SOBER 2013, 51. Anais... Disponível em: <http://icongresso.itarget.com.br/useradm/anais/?clt=ser.3>. Acesso em: 13 ago. 2013.

WEBSTER, Allen L. Estatística Aplicada a Administração e Economia. São Paulo: McGraw Hill. 2006. 